СОЛОВьЕВА Светлана Вадимовна, ведущий научный сотрудник отдела гражданского законодательства зарубежных государств Института законодательства и сравнительного правоведения при Правительстве Российской Федерации, кандидат юридических наук

117218, Россия, г. Москва, ул. Большая Черемушкинская, 34

E-mail: foreign3@izak.ru

В российском гражданском праве не так давно возник новый институт — корпоративный договор, причины появления которого в законодательстве отличаются от тех, что сложились в предпринимательской деятельности корпораций на территории США. Предметом рассмотрения данной статьи является регулирование соглашений держателей акций законами отдельных штатов США. Актуальность этой темы обусловлена неутихающими спорами о природе корпоративного договора и его роли в управлении акционерным обществом. США стали первой страной, в праве которой появился корпоративный договор. Автором рассмотрены причины, побудившие законодателей штатов внести в законы о предпринимательских корпорациях положения о соглашениях держателей акций. Пристальное внимание в статье уделено закрытым корпорациям и их отличиям от предпринимательских корпораций, поскольку первые соглашения стали заключать акционеры именно закрытых предпринимательских корпораций. Отмечается, что закрытая корпорация выделяется законами далеко не всех штатов. В целях подробного рассмотрения содержания соглашений акционеров исследуется структура управления предпринимательской корпорации, которая не предполагает участие акционеров в управлении ею. Все управление сосредоточено в руках совета директоров и назначенных им управляющих. Сегодня подобная ситуация перестала соответствовать интересам акционеров. Стремление управлять корпорацией и участвовать в распределении прибыли акционеры реализуют, заключая акционерные соглашения. Анализируя законодательство штатов, автор выделяет три вида соглашений акционеров, два из которых ранее не были известны общему праву. Обращается внимание, что все нормы, регулирующие акционерные соглашения, содержатся в законах о предпринимательских корпорациях. Именно эти законы, относимые к корпоративному праву, определяют виды, фрорму, срок действия соглашений акционеров, а также их условия и соотношение с положениями устава корпорации.

Ключевые слова: закрытая корпорация, предпринимательские корпорации, соглашение акционеров, корпоративное право, совет директоров, управление корпорацией, законы штатов, голосующий трест.

\title{
TNE LEGAL NATURE OF A CORPORATE AGREEMENT IN THE US LAW
}

S. V. SOLOVIEVA, leading research fellow of the Department of civil legislation of foreign states of the Institute of Legislation and Comparative Law under the Government of the Russian Federation, candidate of legal sciences

34, Bolshaya Cheremushkinskaya st., Moscow, Russia, 117218

E-mail: foreign3@izak.ru

In Russian civil law, not so long ago a new institution emerged - corporate contract. Its emergence in legislation was result of reasons different from those that emerged in the business activities of corporations in the United States. The subject-matter of the presented article is the contract regulation of shareholders by certain states' laws of the United States. The current interest of this topic is the enormous controversy about the nature of the corporate contract and its role in the management of the jointstock company. The United States became the first country with the right to have a corporate contract. The article examines the reasons that prompted state legislators to make provisions on shareholders' agreements in laws on public corporations. Since the first agreements were concluded by shareholders of private corporations, in the article the author pays a special attention to private corporations and their differences from public corporations. The article notes that not all states' laws distinguish the private corporation. In order to examine in details the content of shareholders' agreements, the author examines the structure of the public corporation management, which does not assume the participation of shareholders in the entity's management. The management is in the board of directors' and managers' hands, where the latter is appointed by the former. However this situation does not correspond to the interests of shareholders any more. The desire to manage the corporation and participate in the distribution of profit is exercised by the shareholders through shareholder agreements. Analyzing the state legislation, the author underlines three types of shareholder agreements, where two of them were previously unknown in common law. The article focuses on the 
fact that all rules regulating shareholder agreements are contained in the laws on public corporations. It is these laws that relate to corporate law, determine types, form and effect period of the shareholder agreements, as well as their conditions and correlation with the provisions of the corporation's by-laws.

Keywords: private corporation, public corporations, shareholder agreements, corporate law, board of directors, corporate management, states' law, voting trust.

DOI: 10.12737/art.2018.2.11

B российской правовой действительности корпоративный договор, о котором пойдет речь в статье, появился сравнительно недавно, и его появление в законодательстве было вызвано иными причинами, чем те, что сложились в предпринимательской деятельности корпораций на территории США. С самого начала следует определиться с понятиями, которыми оперирует российское законодательство и законодательство США. В целом они совпадают, но корпоративный договор законы штатов и единообразный закон называют соглашением держателей акций. «Держатели акций» - это термин, который используется в законодательстве штатов и федерации, когда речь идет о членах предпринимательской корпорации. По своей правовой природе предпринимательская корпорация является акционерным обществом, и, как следствие, держатели акций корпорации, безусловно, акционеры, но в законодательной практике США применяется термин «держатели акций», а не «акционеры».

Соглашения акционеров в США регулируются законодательством отдельных штатов, сложившимся на базе единообразных законов, причем довольно скупом. Также необходимо отметить и сильное влияние судебной практики на расширение прав акционеров. Законодательное регулирование акционерных соглашений в США стало осуществляться после принятия штатами законов о предпринимательской корпорации и было обусловлено рядом причин. Однако следует заметить, что такой вид соглашения акционеров, как голосующий трест, регулировался уже первыми законами о деятельности корпораций и положениями общего права.

Появление акционерных соглашений в предпринимательской практике корпораций в США было вызвано желанием акционеров участвовать в управлении делами предпринимательской корпорации, поскольку другой возможности управлять деятельностью корпорации у акционеров не было.

Здесь уместно вспомнить, что согласно действующему законодательству штатов структура управления деятельностью предпринимательских корпораций в США не предполагает участия в ней акционеров. Все управление сосредоточено в руках совета директоров и назначенных ими управляющих. Акционеры полностью отстранены от принятия оперативных управленческих решений и почти не участвуют в выработке стратегических задач и принятии соответствующих решений. Еще до появления первых законов штатов, регулирующих деятельность пред- принимательских корпораций, согласно нормам общего права у акционеров было только право на получение части прибыли корпорации в виде дивидендов и право и обязанность формировать совет директоров. Суды также закрепили за акционерами право принимать решение по таким судьбоносным вопросам, как ликвидация корпорации, ее слияние с другой корпорацией и продажа всех активов корпорации.

Со временем подобная ситуация перестала соответствовать интересам акционеров, поскольку жесткий диктат совета директоров по вопросам определения размера дивидендов и их выплаты не способствовал росту доходов акционеров. Акционеры никак не могли повлиять на порядок распределения прибыли корпорации. Абсолютная бесправность, невозможность влиять на распределение прибыли, недобросовестное поведение членов советов директоров и управляющих, появление новых возможностей для злоупотреблений, усложнившиеся экономические отношения - все перечисленные факторы обусловили принятие законодателями штатов специальных законов, регулирующих деятельность предпринимательских корпораций. Эти законы впоследствии были скорректированы модельным законом о предпринимательской корпорации.

Разработчики модельного закона учли сложившееся настроение держателей акций и судебную практику признания заключаемых акционерами соглашений, направленных на увеличение своего участия в принятии управленческих решений. В законе появились нормы, закрепляющие за акционерами право заключать соглашения различного характе$\mathrm{pa}$, а также положения, характеризующие предусмотренные законом разновидности предпринимательских корпораций.

Первые соглашения акционеров заключались участниками закрытых корпораций, которые отличались от других видов корпораций только отсутствием их акций и других ценных бумаг на биржевом и околобиржевом рынке, ограниченным количеством участников и особым порядком выхода из корпорации. Поясним, что законы не всех штатов выделяли закрытые корпорации как самостоятельный вид корпорации и до принятия модельного закона о предпринимательской корпорации. В законодательных актах штатов закреплялись два подхода к определению закрытой корпорации: закрытая корпорация как особый вид предпринимательской корпорации и закрытая корпорация как статус предпринимательской корпорации. В отдельных штатах (ярким примером 
является штат Нью-Йорк) и сегодня нет ограничений по количественному составу и порядку выхода из корпорации, которую в других штатах называют закрытой корпорацией. Законы тех штатов, в законодательстве которых не используется термин «закрытая корпорация», выделяли раньше, выделяют и сейчас предпринимательские корпорации как корпорации, акции (иные ценные бумаги) которых не котируются на бирже и не торгуются на околобиржевом рынке. Именно публичный оборот ценных бумаг является квалифицирующим признаком и одновременно условием, позволяющим участникам корпорации изменять порядок управления корпорацией и распределения прибыли, установленный законом штата. Но изменять порядок управления корпорацией участники могут не путем заключения акционерного соглашения, как в других штатах, а внесением изменений в зарегистрированный устав корпорации на общем собрании. Причем решение о таком изменении устава принимается единогласно всеми держателями акций и (или) их представителями. Порядок внесения изменений в устав предпринимательской корпорации определяется как законом штата, так и положениями устава.

Законодатели отдельных штатов до разработки модельного закона выделяли закрытую корпорацию как самостоятельный вид корпорации. Однако в ходе подготовки модельного закона о предпринимательской корпорации разработчики внимательно исследовали правовое регулирование деятельности закрытых корпораций в тех штатах, законы которых выделяли этот вид корпорации, и пришли к заключению, что закрытая корпорация не самостоятельный вид корпорации, а разновидность предпринимательской корпорации. На данную корпорацию было предложено распространить нормы модельного закона о предпринимательской корпорации, что закрепило выводы исследователей, что закрытая корпорация не какой-то новый вид корпорации, имеющий квалифицирующие признаки, а лишь разновидность предпринимательской корпорации.

Вместе с тем внутренняя организация управления предпринимательской корпорацией - как закрытой, так и открытой — в соответствии с законами штатов строится по единой схеме и на российский взгляд несколько специфична.

Начнем с того, что «общее собрание акционеров» корпорации законы отдельных штатов, а также модельный закон о предпринимательской корпорации не называют органом управления корпорации. Только в литературе некоторые авторы иногда делают вывод, что общее собрание акционеров принимает определенные решения ${ }^{1}$. Здесь следует пояснить, что в законодательстве штатов, регулирующем порядок соз-

${ }^{1}$ Cм.: Jennings R. W., Buxbaum R. M. Corporations. St. Paul; Minnesota, 1979. P. 230. дания различных видов юридических лиц и их деятельность, отсутствует такое правовое построение, как иерархия органов управления. Законодательство не выделяет различные виды органов юридического лица в соответствии с их компетенцией и порядком формирования. Иными словами, в законах отсутствует какая-либо классификация органов юридического лица.

Если в законе используется термин «орган», то имеется в виду именно высший орган управления юридического лица, поскольку других органов законодательство не выделяет. Законодатели штатов не используют в законотворческой практике такие понятия, как «высший орган управления», «постоянно действующий орган управления», «исполнительный орган». Используется только термин «орган». Понятие «исполнительный орган» замещается понятием «исполнительные директора», которые согласно законодательству являются представителями юридического лица. Такой термин, как «компетенция общего собрания» или «исключительная компетенция общего собрания» в научной литературе и законодательстве в США не используется. Компетенция общего собрания акционеров в законодательстве обозначается как «права акционеров и права, реализуемые путем голосования по определенным вопросам». На наш взгляд, подобная законодательная техника свидетельствует о слабой теоретической разработке понятия юридического лица и инерции восприятия юридического лица как инструмента для достижения цели, а не самостоятельного участника гражданских правоотношений.

Безусловно, закрепленные за участниками права, которые они могут реализовать только путем голосования на общем собрании, и составляют компетенцию общего собрания как органа управления юридического лица. Однако законы штатов не называют общее собрание участников предпринимательской корпорации ни высшим органом управления, ни органом корпорации вообще. Хотя по ряду вопросов решение вправе принимать только держатели акций, и это их исключительное право, которое они не могут никому передать как в предпринимательской корпорации (термин «открытая корпорация» в законах штатов не используется), так и в закрытой предпринимательской корпорации. Исходя из сказанного, акционеры любой корпорации вправе реализовать свои права как путем голосования на общем собрании, так и заключая акционерное соглашение. Вместе с тем подобное логическое построение не исключает возможных противоречий между решением общего собрания и содержанием соглашения. В том числе на устранение возможных несоответствий была направлена законодательная регламентация акционерных соглашений модельным законом. Однако на сегодняшний день явно просматривается тенденция к снижению роли акционерных соглашений, перераспределяющих полномочия сове- 
та директоров в пользу акционеров, иным способом увеличивающих влияние акционеров на управление предпринимательской корпорацией (например, с использованием закрепленной законами ряда штатов возможности полного или частичного отстранения совета директоров от управления деятельностью предпринимательской корпорации через внесение изменений в устав корпорации; данный механизм не был предусмотрен модельным законом, но и никаких запретов на возможность его закрепления законами штатов модельный закон не содержал).

Какие же вопросы относятся к исключительной компетенции общего собрания и голосование по которым может быть предметом договоренностей в соглашениях акционеров любой корпорации? Договоренность членов корпорации в данном случае предполагает только определение порядка голосования по следующим вопросам:

формирование совета директоров путем избрания его членов;

увеличение уставного капитала корпорации, если этот вопрос не передан для решения совету директоров;

разработка и изменение устава и регламента корпорации;

сдача в аренду, продажа или передача (в форме реорганизации) всего имущества корпорации третьему лицу, одобрение необычных особо крупных сделок;

передача всего имущества корпорации третьему лицу для ведения предпринимательской деятельности на время;

соответствующие изменения в устав, связанные с приостановлением предпринимательской деятельности, если это влечет за собой изменение объема прав акционеров по определенным видам акций;

реорганизация путем слияния или через продажу всех активов;

ликвидация корпорации.

Уставом корпорации учредители вправе расширить перечень вопросов, решение по которым принимают только члены корпорации на своем собрании. Таким образом, акционерное соглашение, заключенное между двумя и более акционерами, может содержать порядок голосования, т. е. использования участниками соглашения своего права голоса, или обязанность следовать соглашению о порядке голосования, о котором участники могут договориться, или обязанность голосовать на общем собрании в соответствии с установленной в соглашении процедурой.

Поскольку законодатель признал закрытую корпорацию разновидностью предпринимательской корпорации, необходимо остановиться на появлении и современном существовании закрытой корпорации, тем более что особенности правового положения этой разновидности предпринимательской корпорации отразились на содержании договора, который вправе заключить между собой акционеры корпорации. Со- глашение акционеров предпринимательской корпорации и закрытой предпринимательской корпорации направлены на достижение одних и тех же целей, но сильно различаются по содержанию.

Акционерное соглашение акционеров предпринимательской корпорации, содержащее договоренности по названным вопросам, может повлиять на изменение порядка управления корпорацией акционерами и в какой-то степени позволить вмешаться в порядок распределения прибыли корпорации. Безусловно, законодатели существенно расширили права акционеров, но это расширение незначительно приблизило акционеров к управлению корпорацией.

Только совет директоров вправе согласно законам штатов определять порядок использования прибыли и осуществлять оперативное управление корпорацией. Участники предпринимательской корпорации не вправе своим соглашением изменять положения устава корпорации. Однако подобное утверждение верно только в отношении предпринимательской корпорации, а вот для закрытых предпринимательских корпораций установлено иное соотношение положений устава и соглашения акционеров. Справедливости ради отметим, что ограниченные возможности соглашения держателей акций предпринимательской корпорации в отдельных штатах восполняются законодательно закрепленным механизмом перевода управления корпорацией в руки держателей акций. Суть этого механизма заключается в том, что на собрании акционеры вправе внести в устав изменения, согласно которым они полностью или частично отстраняют совет директоров и всех управляющих от управления корпорацией и берут управление в свои руки, т. е. все вопросы управления или вопросы, определенные уставом, решают путем голосования. Возможность положениями устава предпринимательской корпорации изменить порядок управления, установленный законом, предусмотрена законами только отдельных штатов.

В отличие от соглашения акционеров предпринимательской корпорации соглашение акционеров закрытой корпорации может содержать условия, изменяющие порядок управления корпорацией, установленный уставом, а также порядок распределения прибыли. Иными словами, положения соглашения акционеров закрытой корпорации могут изменять предписания устава закрытой корпорации, когда установленный соглашением акционеров порядок управления корпорацией не соответствует тому, что определено уставом. Вместе с тем акционеры закрытой корпорации вправе заключать соглашения, не изменяющие установленный порядок управления и распределения прибыли, т. е. касающиеся только порядка голосования на общем собрании по вопросам, отнесенным к их компетенции.

Все вышесказанное свидетельствует, что на сегодняшний день законы штатов предусматривают не- 
сколько видов акционерных соглашений. Содержание и число участников этих соглашений зависит от того, акционеры (держатели акций) какой корпорации заключают соглашения. Несмотря на различный подход законодателей штатов к акционерным соглашениям, заключаемым в закрытых предпринимательских корпорациях и предпринимательских корпорациях, можно выделить акционерные соглашения, доступные акционерам любой предпринимательской корпорации, и акционерные соглашения, разрешенные только акционерам закрытой корпорации. Соглашения, доступные акционерам любой предпринимательской корпорации, в свою очередь, условно можно разделить на два вида.

Первый вид акционерного соглашения - соглашение о порядке голосования на общем собрании по всем вопросам компетенции общего собрания. Данный вид акционерного соглашения заключается между двумя и более держателями акций предпринимательской корпорации в простой письменной форме. Под письменной формой соглашения акционеров во всех штатах понимается форма на бумажном носителе. Срок действия этого соглашения ограничивается законом. В большинстве штатов он не превышает 10 лет, но может продлеваться неограниченное число раз в соответствии с установленной законом процедурой. Положения соглашения обязательны только для его участников. Но следует обратить внимание на то обстоятельство, что законы штатов о предпринимательских корпорациях не предусматривают никаких последствий нарушения акционерами обязательств по соглашению. Именно в соглашении акционеры должны определить последствия его нарушения участниками.

Второй вид акционерного соглашения - соглашение о передаче права голоса на общем собрании акционерами, подписавшими соглашение, либо комунибудь из акционеров, либо третьему лицу. Данное соглашение акционеров законы штатов именуют «голосующим трестом», и оно должно быть заключено в простой письменной форме. Участниками названного вида акционерного соглашения наряду с акционерами могут быть и иные лица, например кредитор корпорации, доверительный управляющий акциями корпорации, залогодержатель акций или облигаций корпорации. Голосующий трест часто используется в качестве обеспечения исполнения корпорацией своих договорных обязательств. Во всех штатах срок, на который может быть заключен голосующий трест, законодательно ограничен, как и передача акционерами своих акций по договору в доверительное управление. Заключение акционерного соглашения по передаче права голоса на более длительный срок, чем тот, что установлен законом штата, делает это соглашение недействительным. Например, в штатах Калифорния, Нью-Йорк, Делавэр согласно действующему законодательству голосующий трест заключается на срок не свыше 10 лет. По истечении установленного срока или до его истечения (в данном случае нормы законов штатов различаются) голосующий трест заключается вновь либо продлевается. Данный вид акционерного соглашения подлежит обязательной регистрации в органе, регистрирующем предпринимательские корпорации, и не является конфиденциальным документом в отличие от соглашения акционеров о порядке голосования. Более того, акционеры вправе с ним ознакомиться.

Третий вид акционерного соглашения, если он предусмотрен законами штатов, доступен только акционерам закрытой корпорации. Именно этот вид акционерного соглашения дает возможность акционерам изменить порядок управления корпорацией, установить порядок распределения прибыли, ограничить полномочия совета директоров или полностью лишить совет директоров установленных законом полномочий. Законы штатов содержат перечень положений устава, которые не могут быть изменены соглашением акционеров закрытой корпорации. Особенностью названного вида акционерного соглашения следует считать еще и тот факт, что заключается оно только между всеми участниками закрытой корпорации. Именно участие всех членов корпорации в соглашении снимает вопрос о законности данного вида акционерного соглашения. Обязательное участие всех членов закрытой корпорации в этом виде акционерного соглашения предусматривалось модельным законом о предпринимательской корпорации и не подлежало изменению законами штатов при имплементации модельного закона в законодательство штата. Вместе с тем не во всех штатах законодательством предусмотрен этот вид акционерного соглашения. В отдельных штатах акционеры могут достичь те же цели иными средствами: через перераспределение полномочий или их передачу одному или нескольким участникам путем внесения изменений в устав корпорации. И этот вид соглашения акционеров заключается в простой письменной форме.

В целом указанные виды акционерных соглашений во всех штатах, законодательство которых допускает их заключение, за некоторыми исключениями регулируются законами единообразно. Справедливости ради следует отметить, что это регулирование очень краткое. Законы штатов о предпринимательских корпорациях не определяют ни порядок изменения, ни порядок прекращения соглашения акционеров и не содержат отсылочных норм к законам, регулирующим договорные отношения. При отсутствии законодательного регулирования акционеры в своем соглашении сами должны установить и порядок выхода акционера из соглашения, и порядок присоединения к уже заключенному соглашению, и ответственность за нарушение положений соглашения. В законодательстве ни одного штата нет даже упоминания о применении положений о догово- 
pax к соглашениям акционеров, как этого не было и в модельном законе о предпринимательской корпорации. Скупость законодательного регулирования акционерных соглашений связана, на наш взгляд, с тем, что законодатели до сих пор не преодолели дуализм в договорной практике штатов ${ }^{2}$. Обращает на себя внимание тот факт, что все нормы, регулирующие акционерные соглашения, содержатся в законах о предпринимательских корпорациях. Именно эти законы, относимые к корпоративному праву, определяют виды, форму, срок действия соглашений акционеров, а также их условия и соотношение с положениями устава и регламента корпорации. Ни законы, регулирующие договорные отношения, ни Единообразный торговый кодекс, а вслед за ним торговые кодексы штатов, не содержат указаний на распространение своего действия на акционерные соглашения.

Дело в том, что в законодательной практике отдельных штатов США до сих пор сосуществуют две договорные модели. Процесс их сближения идет интенсивно, но объединение пока не произошло. Ни суды, ни законодатели пока не определились, по какой договорной модели строится акционерное соглашение. Возможно, это обстоятельство во многом и объясняет то, что положения договорного права не применяются к соглашениям акционеров.

\footnotetext{
${ }^{2}$ Подробнее см.: Терновая О. А., Соловьева С. В. Теоретико-правовое сравнительное исследование правовой природы корпоративного договора по праву Франции и США // Журнал зарубежного законодательства и сравнительного правоведения. 2017. № 5. С. 74.
} БИБЛИОГРАФИЧЕСКИЙ СПИСОК

Jennings R. W., Buxbaum R. M. Corporations. St. Paul; Minnesota, 1979.

Терновая О. А., Соловьева С. В. Теоретико-правовое сравнительное исследование правовой природы корпоративного договора по праву Франции и США // Журнал зарубежного законодательства и сравнительного правоведения. 2017 . № 5.
С одной стороны, очевидно, что акционерное соглашение является результатом согласования воль его участников и однозначно свидетельствует о его правовой природе, соответствующей европейской договорной модели, что позволяет распространять на акционерное соглашение нормы, регулирующие предпринимательские договоры. С другой стороны, ни законодатели, ни суды пока не относят акционерные соглашения к предпринимательским договорам. И тому может быть иное объяснение, а именно то, что законодатели относят соглашение акционеров к инструментам корпоративного регулирования, что тоже не очень вписывается в теорию договорной природы юридического лица, преобладающую сегодня в правовой доктрине США.

Из сказанного следует, что в доктрине не сложился определенный взгляд на правовую природу корпоративного договора. То обстоятельство, что соглашение акционеров регулируется нормами корпоративного права, скорее, дело случая, чем результат закрепления научного поиска. В силу сложившейся ситуации необходимость законодательного урегулирования деятельности предпринимательских корпораций повлекла появление положений, регламентирующих соглашения акционеров в законах штатов о предпринимательских корпорациях. Законодательное регулирование выделило три вида акционерных соглашений, два из которых ранее были неизвестны общему праву и праву США. Голосующий трест ранее существовал согласно нормам общего права штатов. Осмысление правовой природы соглашений акционеров, видимо, еще впереди.

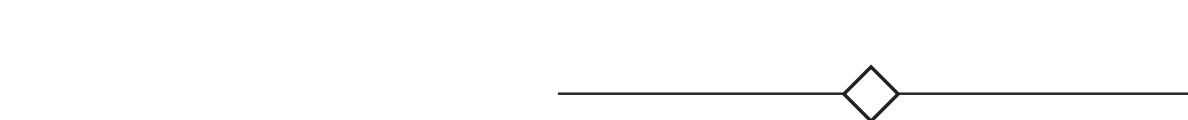

